\title{
WAT VERWAG DIE LIDMAAT HUIDIG VAN DIE PREDIKING
}

(,Preekevaluering” in die praktyk as hulp vir die predikant om huidig suksesvol te kan preek.)

Prof. H. J. J. Bingle

\section{INLEIDING: Ontleding van opdrag:}

Eintlik kan ek nie oor die verwagting van die ,algemene lidmaat" praat nie, omdat daar nie so iets soos 'n algemene „lidmaat" is nie. Daar is seker soveel hoofde, soveel sinne. Prakties kan daar tog 'n min of meer gemene deler aangedui word. Dat ek dit kan doen, wil ek nie voorgee nie. Die ,verwagting" by die lidmaat oor prediking sou ' $n$ mens ook kan noem beoordeling of evaluering omdat ' $n$ mens die Woord van God uitlê. $\mathrm{Al}$ is hy geroepe, preek hy nog nie as heilige mens van God nie (2 Petr. 1 : 21). Hierdie „verwagting" is geen foutvindery nie anders sou ek my hand nie daaraan gewaag het nie. Die lidmaat is geroepe kragtens sy amp as gelowige om hom te verantwoord oor die prediking en veral teenoor die predikant. Ek wil probeer om na die diepte in die eie gemoed te daal om so groter lof aan God te kan toebring deur die geloof wat die prediking werk. Dit is geen homileties-wetenskaplike beoordeling van preke nie. Daarin is ek nie geskool nie en daartoe nie in staat nie. Kom ons vra egter: hoe slyp hierdie yster yster? Hoe slyp een persoon die persoon van 'n ander (Prediker 17:27) deur die prediking in die tydsgewrig waarin ons leef?

\section{DIE GEHOOR VAN DIE PREDIKANT, DIE AANGESPROKENE, DIE GEMEENTE, DIE LIGGAAM VAN CHRISTUS.}

Gelowige mense, nie heidene nie, die mens op weg na die heiligmaking en heerlikmaking en almal is nie ewe ver hierop gevorder nie.

Mense van verskillende grade van volwassenheid; kind; adolossent, volwassene, middeljarige, bejaarde, oue van dae.

Twee geslagte, die twee dele van die mensheid wat teenoor mekaar staan.

Mense van verskillende grade van ontwikkeling.

Mense van verskillende verstandelike, emosionele en rasionele aanleg.

Mense met wisselende grade van erns met die godsdiens.

Mense met verskillende vermoëns van konsentrasie.

Mense met beter en swakker vermoë om te leer, veral verbeel. dend leer.

Die predikant moet nou vir die ,gemiddelde" mens preek soos hy hom vir hom voorstel - net soos ek nou hier namens daardie mens moet praat. 
So werk ons dan met denkbeeldige ,gemiddeldes". Tog is dit nie nutteloos nie. Hieruit mag tog 'n beter begrip van wat met hierdie bespreking beoog word, na vore kom nl.: Wat verwag die lidmaat van die prediking.

\section{WIE IS DAN DIE DENKBEELDIGE HUIDIGE LIDMAAT ?}

Hy leef in ' $n$ unieke tyd soos elke vorige geslag. Hy is nie beter as hulle nie, maar ook nie slegter nie. Hy is egter anders met ander insigte, met ander ,waardes"'. Daarom word hy gewoonlik as slegter beskou a.g.v. die sg. generasie-gaping wat tussen alle opeenvolgende geslagte van alle tye bestaan. As ons dan nou hier na 'n karakteristiek soek, sal daar net een maatstaf vir goed en sleg geld nl. ooreenstemming met of afwyking van die Woord van God.

Die mees tiperende karaktertrek van die moderne mens en daarom ook van die huidige Gereformeerde lidmaat is sy gedemokratiseerdheid, sy wil om deel te hê aan die beheer van alle fasette van sy lewe. Hieruit volg natuurlikerwys 'n houding om alle gesagsituasies wat neig na paternalisme te verwerp. Hy beskou hom as 'n ontvoogde mens t.o.v. alle mense en menslike instellings. $\mathrm{Hy}$ is sy eie baas. Daarmee kom die Woord van God en so God self ook soms in die gedrang. Almal is nie so uitgesproke in hierdie dinge nie, maar by almal het dit sterker of swakker invloed.

Die moderne lidmaat is 'n vat vol teenstrydighede. Selfs botsende standpunte vind binne in hom bestaansreg en dit hinder hom nie. Trouens hy wil nie 'n eenrigting mens wees nie omdat dit met sy grondkaraktertrek bots. Hy is wreed in sy eerlikheid. Hy soek nie maklik doekies om die bloed mee te stop nie. Soos hy binne is, kom hy na buite na vore of dit aanvaarbaar is of nie. Soms kom hy so reëlmatig, robotagtig voor. Wat op's herten grond leid dat melt me naar de keel (Vondel).

Die moderne lidmaat is wreed in sy realisme. Hy staan met altwee sy voete op die grond. Hy dink volgens hierdie rigsnoer. Hy peil alles af na die werklikheid soos hy dit sien, gestroop van alle verdoeseling deur gewoontes of gebruike of instellinge wat bedoel om dinge te verberg of beter of anders voor te stel as wat dit werklik is. Hy wil geen doekies omdraai nie. Hy is nugter soos die werklikheid. Sien ons nie hierin iets van 'n soort van Renaissance wat miskien vir die ouer geslag neig na die platvloerse nie? Die moderne lidmaat beskou dit nie so nie. Hy wil op hierdie wyse by die ware wese van dinge uitkom. Vir die godsdiens lê hierin gevare maar ook groot voordele indien dit simpatiek gelei en verstaan word.

Die noodsaaklike idealisme in gesonde lewensbalans met realisme ontbreek dikwels by die moderne lidmaat. Hy is inherent geskok deur die lewe waarin hy hom bevind. Twee ontsaglike wêreldoorloë dreun na en stamp alle idealisme weg. En tog kan hy nie heeltemal sonder hierdie eg menslike idealisme leef nie!

Die moderne mens beleef elke dag die oorlog sonder bepaalde veldslae, sonder hoogte- en keerpunte, oorlog eenselwig voortdurend aan die gang, sonder iets wat dui op 'n eindelike einde. „Koue 
oorlog" noem ons dit, 'n raak tipering, want dit is wreed koud in die siel en die gemoed van die mensheid van vandag. Dit maak die mens se aardse besitting onseker sodat hy weinig waarde daaraan heg en ook nie graag spaar nie omdat dit letterlik verteer sal word. Oor geestelike besittings sê hy fatalisties: „Kom ek om so kom ek om". Dit lei tot veel erger armoede as die aardse. Hy raak gewoon aan gevaar. Dit laat hom maklik revolusionêr dink en gevaarlik leef. Die natuurlike effek van die dreigende, nl. om weerstand te biel, word vervang deur die bravade wat nie bedoel om gevaar te beveg nie maar om daarmee maats te maak. Dapper op die front domastrant. Die moderne mens is besonder nugter en kalm sodat hy kan aangaan. Hy is tuis in gevaar en hy weet hoe om dit te verteer sodat dit hom nie sal laat ontspoor as mens nie.

Die moderne mens is eienaardig genoeg in staat om ruimtewetenskap en die Woord van God te versoen deurdat hy kragte in die heelal en toepassing van beginsels nie verwar met die ewige waarhede van die geloof nie, al is hy nie in staat om hierdie verskynsel vir homself te formuleer nie. Sy opvoeding en opleiding het 'n diepgang in kennis en wetenskap. Hy word hierin op 'n vroeë lewenstadium so naak gekonfronteer met die geheimenisse van die lewe dat hy 'n vroegrypheid openbaar wat soms vir die geestelike leier verbysterend is. Hierdie mens dring hom in die reël aan niemand op nie, alhoewel hy menigmaal in sy wêreld met sy eie spesifieke problematiek hunker na leiding. Hy maak daarvan geen ophef nie en daarom is dit meesal so moeilik om sy dieptes te bereik.

Hierdie mens is volledig sondaar soos alle mense van alle tye. Hulle wat met die kerk saam leef, weet dit ten volle. Daarom is hy in staat tot ware geloof, want Jesus Christus het ook vir hom gesterf en $\mathrm{Hy}$ ken syne. Hieroor is hy eweneens skugter om te praat, al smag hy ook na die brood van die lewe en ly hy menigmaal honger binne in die kerk. Baie soorte preke gaan sonder sprake by hom verby. Hierdie mens praat 'n eie taal en idioom. Hy het 'n eie lewensidioom wat alleen diegene wat hom met groot erns, simpatie en kennis bejeën, kan verstaan.

\section{VIR HIERDIE MENS WORD NOU GEPREEK}

Niemand is in staat om soveel verskynsels gelyk in sy verstand en gemoed by mekaar te vat en daarin koers aan te dui nie. En tog word dit van die predikant verwag om die soeke van elke lidmaat na die vaste spyse uit die Woord van God te bevredig - 'n ontsaglike onderneming.

Dit is alleen moontlik om vir hierdie mens te preek omdat God self deur die werking van die Heilige Gees leiding gee; die Evangelie en daarmee dan ook God se verbond en beloftes nooit verander nie. Beginsels is eerste dinge en eerste dinge kom van God en is vir ewig vas en onveranderlik soos $\mathrm{Hy}$.

Dit vereis egter dat die prediker sy oor op die dinge sal hou, dat hy gebedsman sal wees en so op die weg van die heiligmaking as Godsman sal staan sonder vrees in ' $n$ siedende en skuimende 


\section{In die Skriflig}

mensewêreld wat 'n mikroverskyning in elke mens van vandag se lewe maak.

\section{WAARNA VERLANG HIERDIE MENS DAN IN DIE PREDIKING?}

Prediking wat mank gaan aan die volgende bevorder nie heilige rapport tussen God en mens nie:

Tekste wat as kapstokke dien vir alles en nog wat; tekste wat nêrens aansluiting vind met lewensbehoeftes nie; Stereotipe aanbiedingstyl ( 3 punte); Parafrase van die Bybelgedeelte; slegs eksegese sonder meer; openbare toespraak i.p.v. 'n preek; emosioneel belaaide aanbieding; koud redelik-filosofiese behandeling; aaneenstrengeling van Bybelse uitsprake sonder om verband te lê; cliche's; 'n prediker wat oneg aangevoel word; taalgebruik wat vreemd staan teenoor die idioom van die tyd; eentonig-vervelig, lustelose aanbieding; deklamerende lawaai moontlik nog met verkeerde aksente; dogmaties droog (moenie dink hy wil nie dogma hoor nie); te stroperig; sonder die krag van die Heilige Gees.

\section{WAT VERWAG DIE GELOWIGE VANDAG IN DIE EREDIENS ?}

In die kerk moet daar 'n ontmoeting tussen God en mens plaasvind. Hierin speel die prediker 'n besondere rol t.o.v. die sang, gebed, Skriflesing, prediking. Langs hierdie weg pas God sy verbondsbelofte toe en die mens staan daarin in sy verantwoordelikheid en in genade. Die mens van vandag smag ook na hierdie gemeenskap met God en met die heiliges.

Die mens wil die volle belewing van die geloof ervaar. Ek haal aan uit Revius, die Totius van die Nederlande van die $17 \mathrm{e}$ eeu:

't Zijn de Joden niet, Heer Jesus die U kruisden

nog die verraderlik $U$ togen voor 't gericht

nog die versmadelik $U$ spogen in 't gezicht -

Ik ben 't, o Heer, ik ben 't die $U$ dit heeft gedaan ....

2 Tim. 3:16: Die hele Skrif is deur God ingegee en is nuttig tot lering, tot wederlegging, tot teregwysing, tot onderwysing in die geregtigheid, sodat die mens van God volkome kan wees, vir elke goeie werk volkome toegerus. 2 Tim. 4:2: verkondig die woord. Spreuke 27:17: Yster slyp yster, so slyp die een mens die persoon van die ander.

Die moderne mens benader by voorkeur die godsdiens en daarmee saam die prediking totalitêr, d.w.s. dit moet vir hom betekenis hê in al die verbande waarin hy hom bevind. Ons sou hier die wetskringe van Dooyeweerd nader kon betrag. Ek wil dit egter liewer kombineer met 'n vroeë uitspraak van Kuyper oor die ensiklopedie van die wetenskap en dit dan so relevant maak t.o.v. die prediking. Die mens staan in 'n hele aantal verbande wat ek kort so wil saamvat: in verband met die wêreld van die stoflike geskapenheid (materie, plant, dier, hemelliggame); in verband met sy eie wese: met sy naaste of medemens in ' $n$ wye spektrum van verbande en laastens in verband met God. Vir my dra dit betekenis vir die prediking. Ek kan sonder aarseling sê dat die mens behoefte daaraan 
het om al hierdie verbande ingetrek te kry in die leiding wat van die kant van die kerk deur die prediking tot hom kom.

Die mens staan vertikaal na onder op die aarde in die natuur met die stoflike, plantlike, dierlike en die hemelliggame as elemente. $\mathrm{Hy}$ is kragtens sy wese ook aardgebonde en verantwoordelik in 'n bewuste en opsetlike verhouding wat God-vererend of Satan-dienend is. Daar moet dus ' $n$ keuse gemaak word en die prediking moet hierin die regte leiding gee sodat die mens volkome toegerus kan wees vir elke goeie werk. God se geskape dinge in die heelal mag nie verag word nie, maar deur die prediking moet die lidmaat langs hierdie weg kom tot die bewondering van God se majesteit. Ons Ned. Geloofsbelydenis spreek van God se skrif met groot en klein letters van sy wonderbare openbaring in die skepping.

Horisontaal staan die mens in ' $n$ verbond met homself en met sy naaste tot selfkennis en selfwaardering en kennis en waardering van sy naaste. Die prediking moet hom aan homself ontdek sodat hy die volheid van sy diensbaarheid aan God kan ken. Daarvoor kom die totaliteit van sy persoonlikheid in aanmerking: sy kenlewe (profetiese amp, Jesus - lering), sy gevoelslewe (priesterlike amp, Heilige Gees - diens), sy strewingslewe (koninklike amp, Vader regering).

Die Woord moet hy met sy hoof vat (ken), moet hy met sy hart beleef en met sy hand uitvoer, alles aan God diensbaar. Hy moet homself liefhê.

Deur die kennis kom die geloof, deur die geloof die aanbidding en deur albei gaan hy heen en sondig nie meer nie.

Maar die betrokkenheid by die beoefening van die godsdiens en daarom ook onder die prediking, strek veel verder as die persoon se verantwoordelikheid teenoor homself. $\mathrm{Hy}$ is ten nouste verbonde aan sy naaste in al die lewensterreine: huislik, familie, sosiologies, ekonomies, staatkundig, juridies, histories, eties, esteties, almal fasette waarin elke mens leef met sy medemens. En vir alles en almal is hierin die beginselriglyn in die Woord van God neergelê. Daarom moet die prediking die mens ook hierin rig en onderrig anders plaas dit 'n uiters belangrike lewensfaset van die mens buite die diensbaarheid aan God. Hy moet die naaste liefhê.

Die mens is vertikaal verbind met die transendente, met God, sy Vader en sy Onderhouer wat hom van bo af vashou, regop hou in al sy verbande. Hy hou hom in die tydelike en die ewige. Hy het hom in sy neerbuigende liefde skaars minder gemaak as die engele om sy troon. Dit bied die sluitsteen vir die prediking: die rapport, die gemeenskap tussen God en die totale mens tot die eer van God en tot sy saligheid.

Die ontsaglike klimaks werk tot in die ewigheid! Hierna smag die mens van vandag in ' $n$ lewe wat ankerloos op vernietiging afstuur. Hierin wil hy deur die prediking gevoed word. Hy wil beleef wat Paulus op pad na Rome beleef het toe hy medegelowiges ontmoet het. Hy het God gedank en moed gevat (Hand. 28:15).

Elke preek is o.a. onderwysend. Gebore uit die groot nood van ons tyd is dit dan voordelig om ag te gee op die elemente waaraan 'n lerende aanbieding moet beantwoord. Dit kan die prediker help 


\section{In die Skriflig}

om vrugbaarder tot die lidmaat te spreek. Die prediker is uit die aard van die saak begaan om wat die Woord van God sê so mee te deel dat dit maksimale betekenis sal hê. Die volgende orde kom hier ter sprake:

\section{ELEMENTE VAN 'N LERENDE AANBIEDING.}

Die stof en doelstelling moet in 'n kragtige stelling aangekondig word sodat elkeen sonder twyfel sal weet wat die tema is. Hiervoor is die voorlees van die teks nie voldoende nie. Die essense van die betekenis moet noodsaaklik in taal, sonder die geykte Bybeltaal en in die idioom van die gemeentelede, aangedui word.

Hierop volg die motivering. Niemand moet in die duister gelaat word waarom daardie teks gekies is nie sodat niemand begin wonder en raai waarom dit gaan nie. Die tekskeuse en motivering is dus ten nouste verbind. Dit moet dadelik die Godsopenbaring relevant mak vir die mens in die tydsgewrig waarin hy leef. Die Bybel is immers onbegrens. Dit staan tegelyk in tyd en ewigheid. Dit wil en moet die mens ervaar.

Daarop volg die analise van die teks deur die eksegese om die volle betekenis en verband van daardie Skrifgedeelte binne die Skrif as geheel (die heilsweg van die Evangelie) te bepaal.

Met die ontwikkeling of uitbouing van die teksinhoud word die volle draagwydte daarvan stap vir stap tot in die volle diepte geëksponeer.

Weinig lidmate kan die volle opset van wat verduidelik is met hulle mee neem om hulle lewens daarna te rig. Daarom is die samevatting samestelling of sintese van wat die teks opgelewer het noodsaaklik, selfs as herhaling om die saak deeglik tuis te bring. Dit moet die gevolgtrekking laat: So sê die Here vir jou as persoon in hierdie preek; dit moet jy weet; dit moet jy beleef; dit moet jy daadwerklik doen as gelowige kind van God op die weg van die heiligmaking wat uitloop op die heerlikmaking in tyd en ewigheid.

\section{8. 'N PAAR NOODSAAKLIKHEDE VIR DIE PREDIKING T.O.V. DIE MODERNE MENS.}

Die leerproses by die mens moet in gedagte gehou word: konsentrasie, appersepsie, assosiasie, geheue, verbeelding. Dit is noodsaaklik dat die prediker hom verantwoord oor die konsentrasievermoë van die lidmaat. Die bestes onder ons kan skaars 20 minute lank ons aandag hou by sulke ernstige stof soos waarom dit in die prediking gaan. Dit is 'n saak van lewe en dood. Gedryf enersyds deur die hartstog om alles te vat en andersyds die vrees dat van die belangrike sake vergeet kan word, bring die lidmaat in geestelike spanning. Om dit vir hom makliker te maak moet appersepsie-massas opgebou word. Daarby moet assosiasies gelê word om sy geheue en begrip te ondersteun sodat hy in staat sal wees om verbeeldend die onsienlike te sien.

Ons het reeds gesê watter taalgebruik vermy moet word. Wat wil die moderne mens dan hê? Hy verlang inkleding in die taal 
wat hy elke dag praat, woorde sowel as frases, sinne en idioom wat hy verstaan, al sal dit soms vir die ouer lidmate eienaardig voorkom. Kom weg van die geykte segginge. Wees onbevange eie in u segswyse en stellinge. Kom na die werklikheid (soos 'n realis) sonder omhaal van woorde. Gebruik by voorkeur kort, stakatosinne, swaar gelaai met die inhoud wat tuisgebring moet word. Gebruik die beelde en voorbeelde van die tyd soos Christus in die gelykenisse gedoen het. Praat by voorkeur 'n taal wat selfs die kinders in die gemeente kan verstaan en u kan seker wees dat diegene hoër op ook sal verstaan.

Uitdrukking, segswyse moet eie aan die tyd en eie aan die lidmate en eie aan die prediker wees. Wend al die moontlikhede aan wat die taal bied om die boodskap tuis te bring: omskrywing, teenstelling, vergelyking, samevatting, herhaling, ander woorde. Kortom, wees tot die uiterste toe vaardig in die medium waardeur die evangelie gedra word, nl. die woord. Vermy te alle tye gemaakte mooi taal, geleerde taal, woordeboektaal, sg. verhewe taal.

Die verskyning en aanbieding van die prediker op die kansel spreek in ' $n$ besondere sin tot die mens van vandag. Met die kanselkleed is deur ons tyd weggedoen. Dit is ' $n$ seën. Die taal is weg van die geykte. Die predikant met die koud verhewe houding in sy ongenaakbaarheid het verdwyn. Die preekstem is 'n argaisme. Dit alles het bygedra om die formalisme af te breek en om sodoende die prediker nader aan die gemeente te bring.

Die houding van die predikant op die kansel moet vry, rustig, op sy gemak, vriendelik, uitnodigend wees. Daarby moet hy met gesag en ontsag praat oor hierdie hoogheilige dinge. Die mens uit die tarde werklikheid het nie lus vir allerlei tierlantyntjies rondom die persoon van die predikant nie. Moenie dink dat hy die predikant saam met hom in die rioolsloot wil sien nie, maar hy wil hoër sfere kan styg.

Die lidmaat wil 'n preek hoor en nie 'n openbare toespraak of 'n wetenskaplike referaat nie. Hierdie voordragte het hulle eie kenmerke. As die preek na hulle kant toe swaai, word die preek slaaf, gebonde en is hy nie langer vry in sy eie reg nie. Hou die preek by sy reëls. Hierdie slawerny voel selfs die oningewyde lidmaat skerp aan al is hy nie by magte om dit te formuleer nie.

\section{EPILOOG}

Ek het gesê dat ek hierdie saak benader vanuit die behoefte van die mens. Dat alles in die eerste plek moet gaan om die eer van God en eers daarna tot redding van die mens word nie hierdeur aangetas nie.Dit is 'n saak van lewe en dood vir die mens. Hy leef in 'n verwarde, veeleisende wêreld waarin sy geloof aan en hoop op verlossing tot die uiterste beproef word. Daarvoor is voorwaar veel genade nodig. Hy is voortdurend blootgestel aan die hamerhoue van die wêreld in al sy verskyninge van fyn, subtiele tot die nuutste wreedheid, aan aanvalle van jou eie mense, sodat die uiteindelike bestaansvraag na vore gedring word. 
Ons moenie te gou met bewysplase uit die Bybel die soekende geloof van die mens wil minimaliseer nie. Derglike uitsprake kan miskien nog die verstand bevredig, maar wat van die hart, gemoed? Die gewisse kennis is veel makliker as die vaste vertroue. Die rus moet gevind word op 'n vlak wat ver bo die denke uitgaan: die sien van die onsienlike. Eers dan sal die hand die dankbaarheidsdaad kan verrig. Kan ons die beproewing en loutering van die kinders van God waarvan ons weet deel van ons eie lewe mak en dan nog by die Belydenis bly in 'n tydsgewrig waarin die mens homself ontvoog het en sulke situasies as sinloos en onverantwoordbaar beoordeel? Hy soek nog. tans na gemeenskap met God - geregtigheid, liefde of hy gly by die Gereformeerde belydenis verby!

Juis dit is die groot taak van die prediking gesien van die kant van die lidmaat: die bewerkstelling van die oorgang van wete na aanvaarding in die geloof. Preek dan oor al die fasette van die geloof en die lewe. Daar kom krississe vir alle kinders van God.

Dink veral ook aan voorskoolse kind, die laerskoolkind, middelbare skoljer voordat belydenis afgelê word. Elkeen het net soos die volwassene behoefte aan die onafgebroke prediking, maar het ander ervaringe en belewinge as die volwassene. Die kind het basies nie behoefie aan troos nie en dus nie aan die orde van die Kategismus se geloofsweg nie. Hy het behoefte aan begrip van die Gans Andere. God en die dinge wat in verband met Hom staan: oorsprong, wese, persone, alles in hierdie verband. Hy het behoefte aan begrip van homself en die wêreld waarin hy leef.

Prediking moet stelselmatig by die kind kum want onderrig soos in die Kategismus is nie voldoende nie. Onderrig moet sodanig in sy lewe ingedra word dat hy saam met kenen as inherente deel van die kenne, gelykmatig diene kan beleef sodat alles vir hom lewensbetekenis kry.

(Referaat gelewer voor GTV Oos-Transvaal op Dinsdag 5 Junie 1979 te Lydenburg). 